\title{
The arsenal of pathogens and antivirulence therapeutic strategies for disarming them
}

This article was published in the following Dove Press journal:

Drug Design, Development and Therapy

27 May 2016

Number of times this article has been viewed

John R Brannon'

Maria Hadjifrangiskou ${ }^{1,2}$

'Division of Molecular Pathogenesis, Department of Pathology, Microbiology and Immunology, ${ }^{2}$ Department of Urologic Surgery, Vanderbilt University School of

Medicine, Nashville, TN, USA
Correspondence: Maria Hadjifrangiskou Department of Pathology, Microbiology and Immunology, Vanderbilt University School of Medicine, II6I 2 Ist Avenue South, Nashville, TN 37232, USA

$\mathrm{Tel}+\mathrm{I} 6159431907$

Fax + I 61534374392

Email maria.hadjifrangiskou@vanderbilt. edu

\begin{abstract}
Pathogens deploy an arsenal of virulence factors (VFs) to establish themselves within their infectious niche. The discovery of antimicrobial compounds and their development into therapeutics has made a monumental impact on human and microbial populations. Although humans have used antimicrobials for medicinal and agricultural purposes, microorganism populations have developed and shared resistance mechanisms to persevere in the face of classical antimicrobials. However, a positive substitute is antivirulence therapy; antivirulence therapeutics prevent or interrupt an infection by counteracting a pathogen's VFs. Their application can reduce the use of broad-spectrum antimicrobials and dampen the frequency with which resistant strains emerge. Here, we summarize the contribution of VFs to various acute and chronic infections. In correspondence with this, we provide an overview of the research and development of antivirulence strategies.
\end{abstract}

Keywords: virulence factors, antivirulence therapeutics, biofilms, regulation, Escherichia coli, quorum sensing, persister cells

\section{The ascent and collapse of conventional antimicrobials}

In 1929, Alexander Fleming described a method for isolating Bacillus influenzae using penicillium mold broth filtrate, which he termed penicillin. ${ }^{1}$ In his report, Fleming emphasized penicillin's use in the bacteriological laboratory and briefly mentioned its potential implications for medicine. Ironically, in that first report, Fleming recommended taking advantage of the innate penicillin resistance of gram-negative bacteria to promote their isolation and identification. ${ }^{1}$ This basic scientific discovery heralded in the golden age of antimicrobials.

Although penicillin launched the age of antimicrobials, prontosil, a sulfonamide discovered by Gerhard Domagk working for IG Farben (Bayer) in 1935, was the first antimicrobial manufactured for therapeutic application. ${ }^{2,3}$ Neisseria and Streptococcus infections were among the first to be widely treated with sulfonamides. ${ }^{2,4,5}$ Penicillin was not available for clinical use until the 1940s, when Ernst Chain and Howard Florey developed a method allowing for mass production. ${ }^{6}$

The abundant use of antibiotics that followed in hospitals and agricultural industry initiated the surfacing of antimicrobial-resistant strains. For example, sulfonamideresistant Neisseria gonorrhoeae isolates became wide spread in the clinical setting shortly after World War II. ${ }^{5}$ Penicillin replaced sulfonamides for treatment, leading to the emergence of penicillin resistance within the next $15-20$ years. ${ }^{7-9}$ Gradually, $N$. gonorrhoeae developed resistance to the vast majority of other classes of antibiotics, including aminoglycosides, tetracycline, macrolides, and most recently fluoroquinolones. ${ }^{10}$ 
In 2007, the United States Centers for Disease Control and Prevention announced cephalosporins as the only remaining option for treating $N$. gonorrhoeae. ${ }^{11}$ Strains with reduced susceptibility to the cephalosporins cefixime and ceftriaxone have since emerged. ${ }^{11}$ Over the past few decades, only one new antimicrobial class was discovered. ${ }^{12}$ The next generation of antimicrobials and therapeutic strategies must withstand the force of microbial evolution; unless, we wish to confront another cohort of "super-bugs".

Antivirulence therapies (AVTs) that target virulence factors (VFs) or their production/regulation constitute an alternative approach to classical antimicrobials. This is in contrast to current cidal or static antimicrobials that disrupt pathogen growth, thereby selecting for mutations that would allow resistant populations to take over. ${ }^{13}$ The aim of many AVTs is to tax bacterial metabolism to a point that pathogens are incapable of paying the "fitness cost" associated with a prospective infectious niche. In addition, commensal microbes are unlikely to produce the targets of AVTs, thus reducing the collateral damage imposed to the host's microbiota by current antimicrobials. However, AVTs require a greater level of forethought in their design and understanding of microbial pathogenesis, which of course come with a greater fiscal burden. In certain cases, effective implementation of AVTs requires rapid diagnostics, which is far from being a new priority in medical research. In this review, we focus on microbial VFs and the latest progress in developing AVTs against them.

\section{A battle of the ages: common virulence traits and antivirulence strategies aimed to combat them Establishing residency through adherence}

Upon introduction to a niche, pathogens are faced with the challenge of remaining "on location" long enough to establish infection. Microorganisms can be swept away by shear forces applied from the movement of biological fluids and host cell cilia. Pathogens can use various extracellular structures for mediating adherence to host cells. Enteropathogenic Escherichia coli (EPEC) rely on bundle-forming pili (BFP) and EspA filaments for microcolony formation and early attachment to intestinal epithelial cells. ${ }^{14-16}$ Volunteers, who ingested wild-type EPEC, exhibited frequent bouts of diarrhea; in contrast, their luckier counterparts, who ingested bfp mutant strains, had negligible symptoms. ${ }^{17}$ EPEC, enterohemorragic E. coli (EHEC), and their murine model counterpart Citrobacter rodentium can form attaching and effacing lesions during infection. These pathogens use type 3 secretion systems (T3SSs) to inject the intimin receptor (Tir) into the host cell. ${ }^{18-20}$ Translocated Tir becomes embedded into the host cell and serves as a bacterial docking mechanism via its interaction with the bacterial intimin protein. ${ }^{18-20}$

Extraintestinal pathogenic E. coli adhere to host cell niches via the use of pili that assemble by the chaperone usher pathway (CUP) system. ${ }^{21-27}$ The proteins adorning the tips of CUP pili are specialized adhesins with stereochemical specificity to distinct moieties depending on the CUP pilus. For example, the adhesin of type 1 pili (Fim), FimH, mediates adherence to the bladder epithelial cells by binding with glycoproteins on the host cell's surface. ${ }^{23,28}$ The pyelonephritisassociated pili ( pap) operon codes for the P pili components; $P$ pili are capped by the $P a p G$ adhesin, which binds specifically to the $\alpha$-D-Gal $p$ - $(1 \rightarrow 4)-\beta$-D-Gal $p$ disaccharide moieties and mediates kidney colonization. ${ }^{29-35}$

\section{Antiadherence strategies to prevent bacterial colonization}

Strategies aiming to prevent bacterial adherence can target the regulatory systems governing adhesin expression, disrupt the secretion of adhesins and their assembly, or block the binding between the bacterial adhesin and host receptor. In EPEC, a vaccine against BFP is in development, inspired by production of antibodies to the BfpA component, in children naturally infected with EPEC. ${ }^{36-38}$ Research delineating the composition and biogenesis of BFP has elucidated the occurrence of two BfpA variants, termed $\alpha$ or $\beta .{ }^{39}$ The minor subunits $\mathrm{BfpJ}, \mathrm{BfpI}$, and $\mathrm{BfpK}$ are also found incorporated in the external BFP filament. ${ }^{40} \mathrm{~A}$ vaccine including both $\mathrm{BfpA}$ versions and Bfp minor units will likely confer a wider range of protection. The capacity of an EPEC vaccine against BFP subunits to elicit a protective and memorable immune response is untested at this time.

Another strategy targeting adhesins is the rational design of host receptor mimicking saccharides, which is heavily sought after for uropathogenic E. coli (UPEC) infections. The vital role of PapG and FimH in mediating adherence to the uroepithelium makes them prime candidates for antivirulence targeting. Analysis of the binding requirements between PapG and the galabiose receptor guided the design of a PapG inhibitor with a superior aptitude for binding to the host receptor than the natural galabiose receptor; the ability of this PapG inhibitor or derivatives to outcompete the galabiose receptor and consequently disrupt UPEC adherence in vivo is a priority for further development. ${ }^{41}$ The same strategy is even further along in development for targeting FimH of UPEC's type 1 pili. FimH inhibitors, or mannosides, are analogous 
to the FimH receptors and sequester available FimH from binding. In murine models, a mannoside was effective in reducing the bladder bacterial burden during acute and chronic cystitis; furthermore, administration of the mannoside made a trimethoprim-sulfamethoxazole-resistant UPEC strain vulnerable to trimethoprim-sulfamethoxazole treatment. ${ }^{42,43}$ Cocrystallization of FimH with mannosides facilitated the engineering of a new mannoside with improved affinity for FimH and increased availability in urine, which further reduced bladder bacterial burden compared to the predecessor compound. ${ }^{44}$

Mannosides have recently been used to target the FimH of adherent-invasive E. coli (AIEC) associated with Crohn's disease $(\mathrm{CD})$ and $E$. coli isolated from osteoarticular (hip replacement) infections. ${ }^{45}$ In a $\mathrm{CD}$ murine model, transgenic CEABAC10 mice, which express the human CECAM6 mannosylated receptor, infected with AIEC LF82, were treated with monovalent mannosides post-infection. ${ }^{46}$ Two mannosides designated 1A-HM and 1CD-HM reduced the bacterial fecal load by $\sim 2.5$ and 3 logs, respectively; AIEC LF82 associated with the ileal and colonic mucosa dropped below the limit of detection and mirrored the uninfected mice. ${ }^{46}$ Furthermore, treatment with 1A-HM and 1CD-HM severely diminished colitis and inflammation. ${ }^{46}$

Disrupting the biogenesis of adherence factors is another promising AVT. Larzabal et $\mathrm{al}^{47}$ synthesized two small peptides corresponding to the $\mathrm{C}$-terminal coiled-coil domain of the EPEC T3SS translocator EspA. These coiled-coil peptides blocked polymerization of EspA disrupting proper T3SS function and formation of attaching and effacing lesion on HEp- 2 cells by EPEC and EHEC. ${ }^{47,48} \mathrm{C} 57 \mathrm{Bl} / 6$ mice inoculated with $C$. rodentium pretreated with both coiledcoil peptides suffered no damage to their colonic epithelium compared to their untreated counterparts. ${ }^{48}$

In UPEC, nonpeptidic, pyridone molecules have been designed to bind specifically to the periplasmic chaperone protein, which escorts CUP pili subunits across the periplasmic space. ${ }^{49}$ The application of chemical synthesis platforms enabled the generation of large-scale 2-pyridone libraries and analysis of various chemical substitutions impacting pilicide potency. ${ }^{50,51}$ Recently, one pilicide, ec240, was shown to act on the transcriptional level repressing transcription of the fim operon. ${ }^{52}$ Ec240 is still in the early stages of preclinical development and its direct target(s) remain unknown.

\section{Evasion of the innate immune system and invading the host}

Initially, pathogens confront innate immune system barriers, including lysozyme and immunoglobulin A (IgA), and antimicrobial peptides (AMPs) ${ }^{53-57}$ Bacteria, such as Yersinia pestis (the causative agent of pneumonic and bubonic plague) and Moraxella catarrhalis (one of the major causes of otitis media), encode lysozyme inhibitors to combat damage by lysozyme. ${ }^{58,59} Y$. pestis mutants with deletion of the ivy gene, which encodes for a lysozyme inhibitor, were attenuated in $Y$. pestis bubonic and primary pneumonic plague rodent models. ${ }^{59}$ Wild-type and $\Delta i v y Y$. pestis strains exhibited indistinguishable virulence potential in FVB lysozyme M-deficient mice, which cannot produce antimicrobial lysozyme LysM. ${ }^{59}$ In the mucosa, IgA helps maintain balance between the host and their microbiota, as well as, dissuade potential pathogens from invading the mucosa. ${ }^{54}$ Streptococcus pneumoniae $\operatorname{IgA} 1$ protease cleaves $\operatorname{IgA} 1$ heavy chain and prevents IgA-dependent killing by human neutrophils in vitro. ${ }^{60}$ In agreement with this in vitro IgA1 protease activity, mice passively immunized with a human monoclonal IgA1 antibody had enhanced protection from intranasal challenge with an IgA1 protease mutant compared to mice challenged with wild-type $S$. pneumoniae. ${ }^{60}$ To counter AMP assault, some pathogens express proteins that proteolytically cleave the AMPs; examples include the EHEC OmpT, C. rodentium $\mathrm{CroP}$, and $Y$. pestis $\mathrm{Pla}$, which are homologues outer membrane proteases of the omptin family. ${ }^{61-64}$ On the other hand, Haemophilus influenzae imports AMPs from the periplasm, using the $\mathrm{ABC}$ transporter SapA, and degrades them for use as nutrient resource. ${ }^{65}$

In addition to defense mechanisms mounted against innate immune barriers, pathogens can actively manipulate the host immune response. Salmonella enterica ser. Typhimurium is equipped with two T3SSs encoded on separate Salmonella pathogenicity islands (SPI-1 and SPI-2) ${ }^{66-68}$ The SPI-1-encoded T3SS is required for invasion of intestinal epithelial cells, and the SPI-2 system to manipulate phagolysosome fate and promote Salmonella's intracellular survival. ${ }^{68-70}$ S. enterica secretes TlpA and SseL effector proteins that restrict a nuclear factor $\kappa \mathrm{B}$-mediated inflammatory response and promote bacterial intracellular survival. ${ }^{71,72}$ Yersinia pseudotuberculosis has a similar anti-inflammatory virulence strategy, the T3SS effector YopJ deubiquitinates $\mathrm{I} \kappa \mathrm{B} \alpha$, thereby preventing formation of free nuclear factor $\kappa \mathrm{B}$ that would induce a proinflammatory response. ${ }^{73}$

\section{Supporting the immune system and impeding bacterial invasion}

An immune boosting therapeutic approach that is regaining popularity is the administration of exogenous AMPs or compounds that bolster the production of endogenous AMPs. 
AMP drugs can potentially be used in combination with compounds that derail AMP resistance mechanisms that are common among pathogens. ${ }^{74} Y$. pestis Pla and Shigella flexneri IcsP omptins are required for dissemination within the host. ${ }^{75-79}$ The small peptide inhibitor aprotinin is the first inhibitor identified to be capable of inhibiting multiple omptin proteases and provides the basis for the construction of future therapeutic agents that can disrupt the role of omptin proteases in AMP resistance of multiple pathogens. ${ }^{80}$ More in-depth research is required to understand the numerous AMP resistance mechanisms before an AVT-supporting AMP is successfully composed.

Salicylidene acylhydrazides inhibit the translocation of effector proteins through the T3SSs of both $S$. enterica ser. Typhimurium and $Y$. pseudotuberculosis in vitro. ${ }^{81,82}$ Importantly, salicylidene acylhadrazides also inhibited invasion of epithelial cells by S. enterica ser. Typhimurium in vitro. ${ }^{82,83}$ These compounds are also effective against Chlamydia trachomatis and S. flexneri T3SSs. ${ }^{84,85}$ However, the mechanism by which these compounds disrupt different T3SSs remains to be fully elucidated.

\section{Nutrient scavenging}

Nutrient acquisition is exceedingly difficult when pathogens have to compete with their fellow microbes and their host begins an attempt to starve them out. Bacterial niche competition can even occur within the same species; $E$. coli strains MG1655, HS, Nissle 1917, and EDL933 compete with one another for various resources during colonization of the murine intestinal lumen. ${ }^{86-88}$ In the intestinal lumen of specific pathogen-free $\mathrm{C} 57 \mathrm{Bl} / 6$ mice, commensal $E$. coli outcompete C. rodentium. ${ }^{89}$ Although prevented from colonizing the lumen, $C$. rodentium invades the intestinal mucosa and infects the epithelial cells inaccessible to commensals. ${ }^{89}$

The host's systems are highly reluctant to give up their needed nutrients, such as $\mathrm{Fe}$, and keep them well guarded. ${ }^{90}$ Host immune cells secrete lipocalin 2 that binds to the $E$. coli siderophore enterochelin disrupting $E$. coli's acquisition of Fe. ${ }^{91}$ In a Staphylococcus aureus murine infection model, neutrophil calprotectin restricts bacterial growth within abscess by limiting the level of available $\mathrm{Mn}^{2+}$ and $\mathrm{Zn}^{2+} .{ }^{90}$ To survive in their ornery host, pathogens have developed intensive means for gathering their provisions. Pathogens are adept at scavenging valuable essential metals such as $\mathrm{Fe}$, $\mathrm{Zn}$, and $\mathrm{Mn}$. Accumulation of Fe can be toxic to bacteria and requires strict regulation. When intracellular $\mathrm{Fe}$ is abundant, the ferric uptake regulator (Fur) binds Fe and represses the transcription of $\mathrm{Fe}$ acquisition systems, thereby avoiding
Fe overload and toxicity. ${ }^{92}$ As the Fe level drops, iron-free Fur poorly binds DNA and the once repressed systems become derepressed and more easily transcribed ${ }^{92}$ Fur also represses the small noncoding RNA (sRNA) RyhB, which negatively regulates the expression of genes whose products utilize or store $\mathrm{Fe} .{ }^{93}$ S. enterica ser. Typhi fur mutants were defective in their invasion of epithelial and macrophage cells; additionally, S. enterica ser. Typhi requires Fur for in vitro intracellular macrophage survival. ${ }^{94}$ UPEC CFT073 $\Delta r y h B$ and $\triangle r y h B \quad \Delta f u r$ mutants are attenuated in murine bladder infection, while $\Delta$ fur is not. ${ }^{95}$ In the absence of RyhB, the corresponding UPEC CFT073 rhyB mutant secreted lower levels of siderophores..$^{95} S$. aureus is equipped with ironregulated surface determinants that allow for the harvesting of Fe from the host's hemoglobin. ${ }^{96,97}$ S. aureus scavenges hemoglobin, extracts, and transfers heme to the cytoplasmic IsdG, a heme monooxygenase, which liberates Fe from heme for use by the bacteria. ${ }^{96,98}$ If too much heme is imported or synthesized by $S$. aureus, the heme sensory two-component system (HssRS) is activated and mediates the upregulation of the heme response transporter (HtrAB), an efflux pump, to avoid heme toxicity. ${ }^{99-101}$

\section{Starving the enemy}

A particularly interesting therapeutic approach to infections is to reestablish healthy microbiota to compete with the disruptive pathogen. After a patient's gut microbiome is disrupted, Clostridium difficile no longer faces resource competition and takes the opportunity to take over the intestine. ${ }^{102}$ The modern fecal microbiota transplant (FMT), initially investigated in the treatment of pseudomembranous enterocolitis in 1958, involves the retrieval of the microbiota from a donor's fecal sample and placed into the intestinal tract of a recipient patient. ${ }^{103}$ FMT has become popular in recent years for treating $C$. difficile recurrent infections. ${ }^{104}$ FMT allows restoration of the microbiota and microbe-microbe competitive interactions. Simplifying the transplantation process and development toward donor pools is likely to contribute to the expansion of FMT use in coming years. ${ }^{105,106}$ The capacity of FMT to treat various intestinal diseases is yet to be fully explored.

Another "starvation" strategy is the use of small molecules that can potentially be used to target iron uptake systems. Outer membrane transporters rely on energy from the ExbB-ExbD-TonB system to bring in siderophores. ${ }^{107}$ Highthroughput screening of a small molecule library revealed 16 compounds that were bacteriostatic against UPEC under iron-limiting growth conditions. ${ }^{108}$ A tonB mutant was not 
sensitive to two of these compounds, suggesting that they disrupted TonB activity. ${ }^{108}$ These small molecules are still in the early stages of investigation. ${ }^{108} \mathrm{Hma}$, IreA, IutA, and FyuA are siderophore receptors highly conserved across UPEC strains found in the bacterial outer membrane and surface exposed, which makes them ideal vaccine candidates. ${ }^{109,110}$ Intranasal immunization with Hma, IreA, IutA, or FyuA elicits a humoral antigen-specific response, and mice were protected against UPEC 1 week after immunization. ${ }^{109,110}$ A long-lasting response to Hma, IreA, and IutA remains undetermined at this point. FyuA immunization generated long-lived plasma cells indicating a potential for lasting memory and specifically protective against UPEC in pyelonephritis infection models. ${ }^{109,111}$

Chemical probes are helpful tools for the molecular dissection of biological systems. ${ }^{112}$ During their investigation of S. aureus HssRS activation by heme, Mike et al ${ }^{113}$ identified compound ' 882 that indirectly activated HssRS by promoting heme biosynthesis. Independent from HssRS activation, ' 882 was bacteriostatic under fermentative conditions and an ' 882 derivative, ' 373 , significantly reduced the bacteria load within liver abscess of $S$. aureus-infected mice. ${ }^{113}$ Chemical modification of the parental ' 822 allowed for two different classes of derivatives with activity specific for HssRS activation or inhibitors of fermentative growth. ${ }^{114}$ While analysis of heme biosynthesis will progress with the usage of HssRS activators, the other new class of compounds represents a promising new scaffold for the development of therapeutics against $S$. aureus infections.

\section{Microbial population dynamics}

A pathogen's virulence is not solely reliant upon the genetic toolbox equipped within an individual cell. In certain cases, microorganisms will work together in a socialistic fashion to benefit the population at large. This survival strategy includes the formation of biofilms, intracellular bacterial communities (IBCs), and "division of labor" among subpopulations. Biofilms are an accumulation of sessile and diverse microbial populations held together by an extracellular matrix, which shields the microorganisms from antibiotic treatment. ${ }^{115,116}$ The extracellular matrix consists of an arrangement of various secreted biomolecules potentially including adhesive fibers, carbohydrate-binding proteins, polysaccharides, and extracellular DNA. ${ }^{115,116}$ Candida albicans and UPEC form biofilms on indwelling medical devices and pose serious health risks. ${ }^{116,117}$ During infection, UPEC enters superficial umbrella epithelial cells. Intracellular UPEC develops biofilm-like pods and replicates prior to release into the lumen to avoid the exfoliation process of the urothelium. ${ }^{28,118,119}$ Upon exodus from the surface epithelial cell, UPEC infects additional surface cells, as well as, invading the exposed underlying epithelial cells. ${ }^{28,118,119}$ Bacteria invading the intermediate epithelium settle quiescent intermediate reservoirs (QIRs) and are safe from antibiotics that abolish the exposed extracelluar. ${ }^{120,121}$ Weeks later, QIR bacteria can emerge from their fallout shelters and reinitiate the infectious cycle. ${ }^{121,122}$ IBC formation is not exclusively an UPEC-specific strategy; Klebsiella pneumoniae and Pseudomonas aeruginosa also invade epithelial cells and form intracellular biofilm-like communities. ${ }^{123,124}$

Within bacterial populations, organized subpopulations are phenotypically distinct and can carry out actions that benefit the entire bacterial community. Y. pseudotuberculosis cells on the peripheral region of a microcolony produce Hmp, a nitric oxide detoxifying enzyme, in response to toxic nitric oxide from the host. ${ }^{125}$ The Hmp producing subpopulation prevents nitric oxide from penetrating the microcolony, and the protected centroid cells are spared the unnecessary $h m p$ expression. ${ }^{125}$ Originally recognized for their persistent survival in the presence of penicillin in the early 1940s, persister cells are genotypically identical to their kin yet metabolically dormant. ${ }^{126}$ The minute persister subpopulation serves as a fail-safe to ensure survival in case of a catastrophic event, such as antibiotic clearance of the metabolically active cells.

Rising evidence indicates that bacterial signaling impacts subpopulation heterogeneity. E. coli cells sensing the presence of indole, which is produced under nutrient-limiting growth conditions, are more likely to enter a persister cell state. ${ }^{127} P$. aeruginosa uses quorum sensing (QS) to coordinate the persister subpopulation numbers during logarithmic phase. ${ }^{128}$ Addition of cell-free spent media from stationary phase cultures or the addition exogenous QS autoinducers pyocyanine or $\mathrm{N}$-(3-oxododecanoyl)-L-homoserine lactone (3OC-HSL) substantially promoted persister cell formation of logarithmic P. aeruginosa cultures. ${ }^{128}$ The autoinducer competence-stimulating peptide controls the transformational competency and biofilm formation of $S$. pneumoniae at low concentrations; however, at high concentrations competencestimulating peptide stalls population growth through stimulating the ComD sensor. ${ }^{129-131}$ These studies highlight the dynamic role of QS in coordinating bacterial populations.

\section{Disturbing the peace of biofilm populations}

Biofilm formation allows bacteria to survive antibiotic treatment. Multiple factors are proposed to contribute to biofilm 
antibiotic tolerance, including persister cell populations, slow growth, and poor antibiotic penetration. Within the past few years, development of platforms for high-throughput screening of chemical libraries has accelerated the discovery of compounds active against $C$. albicans biofilms. ${ }^{132,133} \mathrm{~A}$ family of diazaspirodecane-based compounds was found particularly effective at inhibiting C. albicans biofilm formation. ${ }^{134}$ Not only did the lead candidate, identified as compound 61894700 , disrupt biofilm formation but also filamentation without affecting growth of planktonic cells. ${ }^{134}$ Prophylactic treatment with compound 61894700 in an oral and invasive systemic candidiasis murine models reduced fungal filamentation and decreased disease severity. ${ }^{134}$ Another strategy is to find compounds that sensitize biofilms to currently available drugs. Separately, 2-adamantanamine (AC-17) and azoles are not fungistatic, yet the combination of the two is fungicidal. ${ }^{135}$ In vitro analysis reveals that $\mathrm{AC}$-17-exposed $C$. albicans had disrupted ergosterol and hyphae production. ${ }^{135}$ In a guinea pig cutaneous candidiasis model, treatment of subinhibitory fluconazole or AC-17 did not reduce the Candida tissue burden; nevertheless, dual treatment significantly reduced fungal burden. ${ }^{135}$

UPEC QIR poses the additional challenge of passing the antimicrobial agents through the eukaryotic cells. Accelerating the uroepithelial cell turnover can circumvent this problem by exposing the intracellularly sheltered bacteria. Blango and colleagues ${ }^{136}$ found that in a murine model resurgence of UPEC QIRs can be initiated by inducing exfoliation of bladder epithelial cells with chitosan. UPEC UTI89-infected mice that were treated with chitosan had a significant reduction in bacteria loads within the bladder 3 days posttreatment, compared to mice treated with antibiotics alone. ${ }^{136}$ Chitosan treatment is likely be found to lower the frequency of UPEC UTI recurrence. ${ }^{136}$ The occurrence of UPEC QIR is reported in multiple clinical studies indicating that these intracellular biofilm-like communities are not specific to murine models. ${ }^{137-139}$ Furthermore, the presence of QIR in human UPEC UTIs validates AVTs, targeting this critical step in pathogenesis.

Biofilm tolerance is largely attributed to the presence of a dormant persister subpopulation. ${ }^{140,141}$ The persister subpopulation is associated with the recurrent $P$. aeruginosa infections of cystic fibrosis patients and long-term carriage of Candida by cancer patients prophylactically treated with topical chlorhexidine as part of their oral care. ${ }^{142,143}$ Therapeutics aimed at "resuscitating" persister cells are of particular importance for preventing recurrent infections. The protease ClpP is normally tightly controlled through ATPases; however, in the presence of acyldepsipeptides, ClpP becomes active independent of ATPases. ${ }^{144}$ Without proper regulatory control, ClpP nonspecifically degrades bacterial proteins resulting in autodestruction of the bacterial cell. ${ }^{144}$ In lethal systemic murine infections of E. faecalis and S. aureus, the acyldepsipeptide (ADEP4) rescued $100 \%$ and $80 \%$ of the mice, respectively. ${ }^{144,145}$ Unlike rifampicin, ADEP4 eliminated ciprofloxacin surviving $S$. aureus persister cells in vitro, although a small population of $S$. aureus survived through $c l p P$ null mutations. A combination of rifampicin and ADEP4 effectively abolished $S$. aureus biofilms in vitro and $S$. aureus mouse thigh infections. ${ }^{145}$ This is an example of a combinatorial approach to clear an infection through coordinated targeting of different subpopulations.

Instead of pursuing cells within a microbial population directly, the cells within the population can also be targeted indirectly through severing the intercellular communication systems by which the microbes synchronize their pathogenic efforts. $P$. aeruginosa coordinates biofilm fate and persister cell population through the synthesis and release of the extracellular autoinducer molecule 3OC-HSL. ${ }^{128,146}$ Production of both 3OC-HSL and $N$-butyryl homoserine lactone autoinducers is required for successful lung infection of $P$. aeruginosa in rodent models. ${ }^{147,148}$ A class of compound derived from marine algae Delisea pulchra called furanones disrupts the 3OC-HSL sensory system of $P$. aeruginosa and sensitized biofilms to tobramycin killing in vitro. ${ }^{149}$ Administration of furanones C30 and C56 extended the survival time of mice with lethal pulmonary $P$. aeruginosa infections. ${ }^{148,149}$ By interfering with quorum sensory, furanones disrupt the expression of VFs. This disruption of VFs may potentiate the activity of conventional antibiotics that struggle to clear biofilms.

\section{Regulatory systems of pathogens}

To prevent excessive metabolic expenditure, microorganisms closely regulate their core metabolic processes, such as with the fur system previously discussed. Bacterial pathogens can monitor and react to their extracellular environments through two-component sensory systems (TCSs) comprised of a sensor kinase and a response regulator (RR). Typically, upon stimulation, the sensor kinase undergoes autophosphorylation and in turn phosphorylates and activates the RR. The QS E. coli (QseBC) TCS deviates from the customary signal transference cascade. Proper expression of the QseB regulon is tightly controlled through QseC. ${ }^{150,151}$ Deletion of qseC in UPEC UTI89 leads to virulence attenuation in a murine UTI model plus misregulation of curli, pili, flagella, and core 
metabolic processes, whereas UPEC UTI $\Delta q s e B$ and $\Delta q s e B C$ do not display reduction in virulence. ${ }^{150,151}$ This contradiction to the conventional TCS model is explained by the ability of QseC to dephosphorylate QseB and allow expression of the QseB repressed genes. ${ }^{151}$ The PhoPQ TCS is critical for the regulation of VF of $S$. enterica, UPEC, $C$. rodentium, and $P$. aeruginosa. ${ }^{64,152-154}$ Stimulation of the sensor PhoQ by low cation concentrations, acidic $\mathrm{pH}$, and AMP induces canonical activation of the regulatory PhoP. ${ }^{155}$ S. enterica ser. Typhi strains with deletion of $p h o P Q$ were constructed for the development of live attenuated oral vaccine. ${ }^{156,157}$ Although these strains did not elicit a strong immunogenic response, they were profoundly attenuated in virulence. ${ }^{156,157}$ The reliance of $S$. enterica on PhoPQ during infection is attributed to the ability of PhoPQ to coordinate restructuring of the outer membrane. ${ }^{155}$

sRNAs are an additional regulatory layer of pathogens to control their transcripts. E. coli, P. aeruginosa, S. aureus, and Vibrio cholerae can use sRNA to moderate their production of VFs. ${ }^{158-161}$ In E. coli, the master regulator phoPQ mRNA is regulated by MicA and GcvB, which are sRNAs stabilized by host factor Q. ${ }^{162,163} \mathrm{MicA}$ and GcvB both regulate phoP mRNA translation to different extents, which is reflected in their different effects on the PhoP regulon. ${ }^{163}$ $V$. cholerae and Vibrio harveyi have complex regulatory network to modulate their QS pathways. At low cell density and autoinducer concentrations, the QS receptors LuxPQ, LuxN, and CqsS transfer phosphate through LuxU to the RR LuxO. ${ }^{164-167}$ Phosphorylated LuxO promotes the transcription of the four quorum regulatory rna loci (qrr1-4). ${ }^{158,168,169}$ These Qrr sRNAs redundantly repress and activate the translation of the high cell density HapR and low cell density AphA master regulators, respectively. ${ }^{169-172}$ This regulatory system is reversed in high-density populations with high autoinducer production. ${ }^{169,173}$ The Vibrio QS regulatory network seems to allow prioritization of VF production. The Qrr sRNAs directly repress the large type 6 secretion system (T6SS) cluster, which encodes the secretory machinery, and indirectly represses T6SS effectors that are activated by HapR. ${ }^{171}$ The response of Qrr sRNAs genes, such as those encoding for T6SS, directly targeted is relatively more rapid compared to those indirectly regulated through HapR. ${ }^{171,172}$

\section{Communication breakdown}

The disruption of genetic regulatory systems within pathogens poses an option to target multiple virulence systems with one blow and drive the microbe's virulence to ruin. Misregulation of VF genes results in attenuation. AVTs can block signal detection or inhibit signal relay between the sensor and regulator. The compound LED209 prevents the autophosphorylation of the EHEC sensor QseC. ${ }^{174}$ Although LED209 treatment failed to prevent EHEC from intestinal colonization in rabbits, LED209 treatment pre- and postinoculation of $S$. enterica ser. Typhimurium and Franceisella tularensis modestly improved the survival rates of mice. ${ }^{174,175}$ LED209 demonstrates the feasibility of targeting virulence regulatory systems, and future LED209 derivatives may have improved bioavailability and efficacy during infection. ${ }^{174,175}$ The QseBC system cross-interacts with the PmrAB system associated with polymyxin resistance. ${ }^{176}$ In the absence of QseC, PmrB favorably phosphorylates QseB, which would normally be dephosphorylated by QseC. ${ }^{176}$ QseC and PmrB balance out the level of active QseB. This delicate harmonization is reflected during UPEC infection models. In a UPEC model for acute UTI, UPEC UTI89 $\Delta q s e C$ forms significantly fewer IBCs than wild type, and deletion of $p m r B$ in the UTI89 $\Delta q s e C$ strain restores IBC abundance to wildtype levels. ${ }^{176,177}$ An AVT that promotes the buildup of QseB to diminish UPEC virulence by increasing phosphorylated QseB through enhancing the PmrB kinase and/or inhibiting QseC phosphatase activities would be ideal. ${ }^{176}$

The Vibrio QS network contains multiple promising targets, including signal receptors and gene regulators. ${ }^{178}$ A pro-QS strategy is proposed to disrupt the QS signaling cascade and expression of VF between low and high cell density population transitions. ${ }^{179,180}$ One class of compounds was found that inhibits the ATPase action of phosphorylated LuxO and consequently disrupted regulation of the downstream QS circuitry. ${ }^{178}$ Analysis of the biosynthesis of the autoinducer CAI-1 identified the intermediate product Ea-CAI-1 as more potent agonist than CAI-1. ${ }^{181}$ Recently, stable derivatives of Ea-CAI-1 were developed. The most stable Ea-CAI-1 derivative, compound 18, is approximately tenfold more potent than CAI-1. ${ }^{179}$ Compound 18 does not display toxicity to murine fibroblast cells or disrupt the growth of $V$. cholerae. ${ }^{179}$ The ability of compound 18 to improve $V$. cholerae infection remains to be tested. These studies demonstrate the validity of prosignaling therapeutics strategies, promoting the suppression of VFs. These AVTs may also be applicable to other sensory systems, such as with the MerR-like transcriptional regulator BluR in E. coli. BluR is a repressor of $y m g A$ and $y m g B .{ }^{182}$ In the presence of blue-light irradiation, BluF, a flavin binding sensor, binds and antagonizes BluR allowing for the transcription of $y m g A$ and $y m g B$, which promote biofilm formation through the RcsCDB phosphorelay system. ${ }^{182}$ Blue-light irradiation was recently 
shown to deter growth of $E$. coli in a strain and growth phase-dependent manner, as well as, induce a persister-like state in some of the cells, which may involve BluFR light sensing (Mitchell et al, unpublished data, 2016). In sum, the targeting of virulence regulation both at the transcriptional and translational levels is a very promising prospect that has many avenues open for exploration and development.

\section{Conclusion and outlook}

Commensal microorganisms maintain a delicate balance with their host. Pathogenic microorganisms acquire VF stochastically and via selective pressures and use them to misbehave in a niche-dependent manner. During the 20th century, classical antimicrobials have helped to strike back at pathogens; nevertheless, the pathogen menace is equipped with strategies to resist antimicrobials and return for their revenge. The widespread usage of antimicrobials awakened a force of resistance mechanisms, which we must confront to thwart the postantibiotic era we are facing. The quagmire of antibiotic resistance has reached such an extraordinary level that it has finally captured the interest of politicians. In 2014, US President Obama signed Executive Order 13676: Combating Antibiotic-Resistant Bacteria, which called for the formation of Task Force for Combatting Antimicrobial-Resistant Bacteria. ${ }^{183}$ The plan of action outlined by the task force set in place under this executive order prioritizes the development of alternative antimicrobials, such as AVTs, and next-generation diagnostic tools. ${ }^{184} \mathrm{We}$ are at a critical point where necessity is motivating the development of new discovery platforms. Many questions remain to be answered. AVTs represent a new hope for starting a silver age of antibiotics.

\section{Disclosure}

The authors report no conflicts of interest in this work.

\section{References}

1. Fleming A. On the antibacterial action of cultures of a penicillium, with special reference to their use in the isolation of B. influenzae. Br J Exp Pathol. 1929;10(3):226-236.

2. Wainwright M, Kristiansen JE. On the 75 th anniversary of prontosil. Dyes Pigm. 2011;88(3):231-234.

3. Domagk G. Ein beitrag zur chemotherapie der bakteriellen Infektionen [A contribution to the chemotherapy of bacterial infections]. DMW. 1935;61(07):250-253. German.

4. Kampmeier RH. Introduction of sulfonamide therapy for gonorrhea. Sex Transm Dis. 1983;10(2):81-84.

5. Dunlop EM. Gonorrhoea and the sulphonamides. Br J Vener Dis. 1949; 25(2):81-83.

6. Chain E, Florey HW, Gardner AD, Heatley NG. Penicillin as a chemotherapeutic agent. Lancet. 1940;236(6104):226-228.

7. Willcox RR. A survey of problems in the antibiotic treatment of gonorrhoea. With special reference to South-East Asia. Br J Vener Dis. 1970; 46(3):217-242.
8. Ashford WA, Golash RG, Hemming VG. Penicillinase-producing Neisseria gonorrhoeae. Lancet. 1976;2(7987):657-658.

9. Phillips I. B-Lactamase-producing, penicillin-resistant gonococcus. Lancet. 1976;308(7987):656-657.

10. Workowski KA, Berman SM, Douglas JM Jr. Emerging antimicrobial resistance in Neisseria gonorrhoeae: urgent need to strengthen prevention strategies. Ann Intern Med. 2008;148(8):606-613.

11. Workowski KA, Bolan GA; Centers for Disease Control and Prevention. Sexually transmitted diseases treatment guidelines, 2015. MMWR Recomm Rep. 2015;64(RR-03):1-137.

12. Ling LL, Schneider T, Peoples AJ, et al. A new antibiotic kills pathogens without detectable resistance. Nature. 2015;517(7535):455-459.

13. Rasko DA, Sperandio V. Anti-virulence strategies to combat bacteriamediated disease. Nat Rev Drug Discov. 2010;9(2):117-128.

14. Cleary J, Lai LC, Shaw RK, et al. Enteropathogenic Escherichia coli (EPEC) adhesion to intestinal epithelial cells: role of bundle-forming pili (BFP), EspA filaments and intimin. Microbiology. 2004;150(pt 3): 527-538.

15. Daniell SJ, Takahashi N, Wilson R, et al. The filamentous type III secretion translocon of enteropathogenic Escherichia coli. Cell Microbiol. 2001;3(12):865-871.

16. Giron JA, Ho AS, Schoolnik GK. An inducible bundle-forming pilus of enteropathogenic Escherichia coli. Science. 1991;254(5032):710-713.

17. Bieber D, Ramer SW, Wu CY, et al. Type IV pili, transient bacterial aggregates, and virulence of enteropathogenic Escherichia coli. Science. 1998;280(5372):2114-2118.

18. Deng W, Vallance BA, Li Y, Puente JL, Finlay BB. Citrobacter rodentium translocated intimin receptor (Tir) is an essential virulence factor needed for actin condensation, intestinal colonization and colonic hyperplasia in mice. Mol Microbiol. 2003;48(1):95-115.

19. DeVinney R, Stein M, Reinscheid D, Abe A, Ruschkowski S, Finlay BB. Enterohemorrhagic Escherichia coli O157: $\mathrm{H} 7$ produces Tir, which is translocated to the host cell membrane but is not tyrosine phosphorylated. Infect Immun. 1999;67(5):2389-2398.

20. Kenny B, DeVinney R, Stein M, Reinscheid DJ, Frey EA, Finlay BB. Enteropathogenic E. coli (EPEC) transfers its receptor for intimate adherence into mammalian cells. Cell. 1997;91(4):511-520.

21. Miyazaki J, Ba-Thein W, Kumao T, Akaza H, Hayashi H. Identification of a type III secretion system in uropathogenic Escherichia coli. FEMS Microbiol Lett. 2002;212(2):221-228.

22. Subashchandrabose S, Hazen TH, Rasko DA, Mobley HL. Draft genome sequences of five recent human uropathogenic Escherichia coli isolates. Pathog Dis. 2013;69(1):66-70.

23. Martinez JJ, Mulvey MA, Schilling JD, Pinkner JS, Hultgren SJ. Type 1 pilus-mediated bacterial invasion of bladder epithelial cells. EMBO J. 2000;19(12):2803-2812.

24. Mellata M, Dho-Moulin M, Dozois CM, et al. Role of virulence factors in resistance of avian pathogenic Escherichia coli to serum and in pathogenicity. Infect Immun. 2003;71(1):536-540.

25. Stacy AK, Mitchell NM, Maddux JT, et al. Evaluation of the prevalence and production of Escherichia coli common pilus among avian pathogenic E. coli and its role in virulence. PLoS One. 2014;9(1):e86565.

26. Korhonen TK, Valtonen MV, Parkkinen J, et al. Serotypes, hemolysin production, and receptor recognition of Escherichia coli strains associated with neonatal sepsis and meningitis. Infect Immun. 1985; 48(2):486-491.

27. Waksman G, Hultgren SJ. Structural biology of the chaperone-usher pathway of pilus biogenesis. Nat Rev Microbiol. 2009;7(11):765-774.

28. Mulvey MA, Lopez-Boado YS, Wilson CL, et al. Induction and evasion of host defenses by type 1-piliated uropathogenic Escherichia coli. Science. 1998;282(5393):1494-1497.

29. Kallenius G, Mollby R, Svenson SB, et al. Occurrence of P-fimbriated Escherichia coli in urinary tract infections. Lancet. 1981;2(8260-8261): 1369-1372.

30. Norgren M, Normark S, Lark D, et al. Mutations in E. coli cistrons affecting adhesion to human cells do not abolish Pap pili fiber formation. EMBO J. 1984;3(5):1159-1165. 
31. Normark S, Lark D, Hull R, et al. Genetics of digalactoside-binding adhesin from a uropathogenic Escherichia coli strain. Infect Immun. 1983;41(3):942-949.

32. Hultgren SJ, Lindberg F, Magnusson G, Kihlberg J, Tennent JM, Normark S. The PapG adhesin of uropathogenic Escherichia coli contains separate regions for receptor binding and for the incorporation into the pilus. Proc Natl Acad Sci U S A. 1989;86(12):4357-4361.

33. Leffler H, Edén CS. Chemical identification of a glycosphingolipid receptor for Escherichia coli attaching to human urinary tract epithelial cells and agglutinating human erythrocytes. FEMS Microbiol Lett. 1980;8(3):127-134.

34. Vaisanen V, Elo J, Tallgren LG, et al. Mannose-resistant haemagglutination and $\mathrm{P}$ antigen recognition are characteristic of Escherichia coli causing primary pyelonephritis. Lancet. 1981;2(8260-8261):1366-1369.

35. Nilsson U, Striker RT, Hultgren SJ, Magnusson G. PapG adhesin from $E$. coli $\mathrm{J} 96$ recognizes the same saccharide epitope when present on whole bacteria and as isolated protein. Bioorg Med Chem. 1996; 4(11):1809-1817.

36. Schriefer A, Maltez JR, Silva N, Stoeckle MY, Barral-Netto M, Riley LW. Expression of a pilin subunit BfpA of the bundle-forming pilus of enteropathogenic Escherichia coli in an aroA live Salmonella vaccine strain. Vaccine. 1999;17(7-8):770-778.

37. Levine MM. Escherichia coli that cause diarrhea: enterotoxigenic, enteropathogenic, enteroinvasive, enterohemorrhagic, and enteroadherent. J Infect Dis. 1987;155(3):377-389.

38. Martinez MB, Taddei CR, Ruiz-Tagle A, Trabulsi LR, Giron JA. Antibody response of children with enteropathogenic Escherichia coli infection to the bundle-forming pilus and locus of enterocyte effacementencoded virulence determinants. J Infect Dis. 1999;179(1):269-274.

39. Blank TE, Zhong H, Bell AL, Whittam TS, Donnenberg MS Molecular variation among type IV Pilin (bfpA) genes from diverse enteropathogenic Escherichia coli strains. Infect Immun. 2000;68(12): $7028-7038$.

40. Martinez de la Pena CF, De Masi L, Nisa S, et al. BfpI, BfpJ, and $\mathrm{BfpK}$ minor pilins are important for the function and biogenesis of bundle-forming pili expressed by enteropathogenic Escherichia coli. J Bacteriol. 2015;198(5):846-856.

41. Ohlsson J, Jass J, Uhlin BE, Kihlberg J, Nilsson UJ. Discovery of potent inhibitors of PapG adhesins from uropathogenic Escherichia coli through synthesis and evaluation of galabiose derivatives. Chembiochem. 2002;3(8):772-779.

42. Cusumano CK, Pinkner JS, Han Z, et al. Treatment and prevention of urinary tract infection with orally active FimH inhibitors. Sci Transl Med. 2011;3(109):109ra115.

43. Totsika M, Kostakioti M, Hannan TJ, et al. A FimH inhibitor prevents acute bladder infection and treats chronic cystitis caused by multidrug-resistant uropathogenic Escherichia coli ST131. J Infect Dis. 2013;208(6):921-928.

44. Jarvis C, Han Z, Kalas V, et al. Antivirulence isoquinolone mannosides: optimization of the biaryl aglycone for FimH lectin binding affinity and efficacy in the treatment of chronic UTI. ChemMedChem. 2016;11(4):367-373.

45. Chalopin T, Brissonnet Y, Sivignon A, et al. Inhibition profiles of monoand polyvalent FimH antagonists against 10 different Escherichia coli strains. Org Biomol Chem. 2015;13(46):11369-11375.

46. Sivignon A, Yan X, Alvarez Dorta D, et al. Development of heptylmannoside-based glycoconjugate antiadhesive compounds against adherent-invasive Escherichia coli bacteria associated with Crohn's disease. MBio. 2015;6(6):e1298-e1315.

47. Larzabal M, Mercado EC, Vilte DA, Salazar-Gonzalez H, Gataldi A, Navarro-Garcia F. Designed coiled-coil peptides inhibit the type three secretion system of enteropathogenic Escherichia coli. PLoS One. 2010;5(2):e9046.

48. Larzábal M, Zotta E, Ibarra C, et al. Effect of coiled-coil peptides on the function of the type III secretion system-dependent activity of enterohemorragic Escherichia coli $\mathrm{O} 157$ : $\mathrm{H} 7$ and Citrobacter rodentium. Int J Med Microbiol. 2013;303(1):9-15.
49. Svensson A, Larsson A, Emtenas H, et al. Design and evaluation of pilicides: potential novel antibacterial agents directed against uropathogenic Escherichia coli. Chembiochem. 2001;2(12):915-918.

50. Han Z, Pinkner JS, Ford B, et al. Lead optimization studies on FimH antagonists: discovery of potent and orally bioavailable ortho-substituted biphenyl mannosides. J Med Chem. 2012;55(8):3945-3959.

51. Chorell E, Pinkner JS, Phan G, et al. Design and synthesis of C-2 substituted thiazolo and dihydrothiazolo ring-fused 2-pyridones: pilicides with increased antivirulence activity. J Med Chem. 2010; 53(15):5690-5695.

52. Greene SE, Pinkner JS, Chorell E, et al. Pilicide ec240 disrupts virulence circuits in uropathogenic Escherichia coli. MBio. 2014;5(6):e02038.

53. Fleming A, Allison VD. Observations on a bacteriolytic substance ("lysozyme") found in secretions and tissues. Br J Exp Pathol. 1922; 3(5):252-260.

54. Macpherson AJ, McCoy KD, Johansen FE, Brandtzaeg P. The immune geography of IgA induction and function. Mucosal Immunol. 2008;1(1):11-22.

55. Russell JP, Diamond G, Tarver AP, Scanlin TF, Bevins CL. Coordinate induction of two antibiotic genes in tracheal epithelial cells exposed to the inflammatory mediators lipopolysaccharide and tumor necrosis factor alpha. Infect Immun . 1996;64(5):1565-1568.

56. Vora P, Youdim A, Thomas LS, et al. $\beta$-defensin- 2 expression is regulated by TLR signaling in intestinal epithelial cells. J Immunol. 2004;173(9):5398-5405.

57. Rivas-Santiago B, Hernandez-Pando R, Carranza C, et al. Expression of cathelicidin LL-37 during Mycobacterium tuberculosis infection in human alveolar macrophages, monocytes, neutrophils, and epithelial cells. Infect Immun. 2008;76(3):935-941.

58. Joslin SN, Pybus C, Labandeira-Rey M, et al. A Moraxella catarrhalis two-component signal transduction system necessary for growth in liquid media affects production of two lysozyme inhibitors. Infect Immun. 2015;83(1):146-160.

59. Derbise A, Pierre F, Merchez M, et al. Inheritance of the lysozyme inhibitor Ivy was an important evolutionary step by Yersinia pestis to avoid the host innate immune response. J Infect Dis. 2013;207(10):1535-1543.

60. Janoff EN, Rubins JB, Fasching C, et al. Pneumococcal IgA1 protease subverts specific protection by human IgA1. Mucosal Immunol. 2014;7(2):249-256.

61. Galvan EM, Lasaro MA, Schifferli DM. Capsular antigen fraction 1 and Pla modulate the susceptibility of Yersinia pestis to pulmonary antimicrobial peptides such as cathelicidin. Infect Immun. 2008; 76(4):1456-1464.

62. Thomassin JL, Brannon JR, Gibbs BF, Gruenheid S, Le Moual H. OmpT outer membrane proteases of enterohemorrhagic and enteropathogenic Escherichia coli contribute differently to the degradation of human LL-37. Infect Immun. 2012;80(2):483-492.

63. Brannon JR, Thomassin JL, Gruenheid S, Le Moual H. Antimicrobial peptide conformation as a structural determinant of omptin protease specificity. J Bacteriol. 2015;197(22):3583-3591.

64. Le Sage V, Zhu L, Lepage C, et al. An outer membrane protease of the omptin family prevents activation of the Citrobacter rodentium $\mathrm{PhoPQ}$ two-component system by antimicrobial peptides. Mol Microbiol. 2009; 74(1):98-111.

65. Shelton CL, Raffel FK, Beatty WL, Johnson SM, Mason KM. Sap transporter mediated import and subsequent degradation of antimicrobial peptides in Haemophilus. PLoS Pathog. 2011;7(11):e1002360.

66. Hensel M, Shea JE, Raupach B, et al. Functional analysis of ssaJ and the ssaK/U operon, 13 genes encoding components of the type III secretion apparatus of Salmonella pathogenicity island 2. Mol Microbiol. 1997;24(1):155-167.

67. Ochman H, Soncini FC, Solomon F, Groisman EA. Identification of a pathogenicity island required for Salmonella survival in host cells. Proc Natl Acad Sci U S A. 1996;93(15):7800-7804.

68. Galan JE, Curtiss R. Cloning and molecular characterization of genes whose products allow Salmonella typhimurium to penetrate tissue culture cells. Proc Natl Acad Sci U S A. 1989;86(16):6383-6387. 
69. Cirillo DM, Valdivia RH, Monack DM, Falkow S. Macrophagedependent induction of the Salmonella pathogenicity island 2 type III secretion system and its role in intracellular survival. Mol Microbiol. 1998;30(1):175-188.

70. Pfeifer CG, Marcus SL, Steele-Mortimer O, Knodler LA, Finlay BB. Salmonella typhimurium virulence genes are induced upon bacterial invasion into phagocytic and nonphagocytic cells. Infect Immun. 1999; 67(11):5690-5698.

71. Newman RM, Salunkhe P, Godzik A, Reed JC. Identification and characterization of a novel bacterial virulence factor that shares homology with mammalian Toll/interleukin-1 receptor family proteins. Infect Immun. 2006;74(1):594-601.

72. Mukherjee S, Orth K, Krajewski S. Salmonella secreted factor L deubiq-

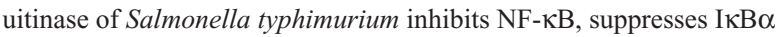
ubiquitination and modulates innate immune responses. J Immunol. 2008;180(7):5045-5056.

73. Zhou H, Monack DM, Kayagaki N, Wertz I. Yersinia virulence factor YopJ acts as a deubiquitinase to inhibit NF- $\mathrm{KB}$ activation. $J$ Exp Med. 2005;202(10):1327-1332.

74. Le Moual H, Thomassin J-L, Brannon JR. Antimicrobial peptides as an alternative approach to treat bacterial infections. J Clin Cell Immunol. 2013;S13:004

75. Shere KD, Sallustio S, Manessis A, D’Aversa TG, Goldberg MB. Disruption of IcsP, the major Shigella protease that cleaves IcsA, accelerates actin-based motility. Mol Microbiol. 1997;25(3):451-462.

76. Welkos SL, Friedlander AM, Davis KJ. Studies on the role of plasminogen activator in systemic infection by virulent Yersinia pestis strain C092. Microb Pathog. 1997;23(4):211-223.

77. Sodeinde OA, Subrahmanyam YV, Stark K, Quan T, Bao Y, Goguen JD A surface protease and the invasive character of plague. Science. 1992; 258(5084):1004-1007.

78. Egile C, d'Hauteville H, Parsot C, Sansonetti PJ. SopA, the outer membrane protease responsible for polar localization of IcsA in Shigella flexneri. Mol Microbiol. 1997;23(5):1063-1073.

79. Lathem WW, Price PA, Miller VL, Goldman WE. A plasminogenactivating protease specifically controls the development of primary pneumonic plague. Science. 2007;315(5811):509-513.

80. Brannon JR, Burk DL, Leclerc JM, et al. Inhibition of outer membrane proteases of the omptin family by aprotinin. Infect Immun. 2015;83(6): 2300-2311.

81. Nordfelth R, Kauppi AM, Norberg HA, Wolf-Watz H, Elofsson M. Small-molecule inhibitors specifically targeting type III secretion. Infect Immun. 2005;73(5):3104-3114.

82. Hudson DL, Layton AN, Field TR, et al. Inhibition of type III secretion in Salmonella enterica serovar Typhimurium by small-molecule inhibitors. Antimicrob Agents Chemother. 2007;51(7):2631-2635.

83. Negrea A, Bjur E, Ygberg SE, Elofsson M, Wolf-Watz H, Rhen M. Salicylidene acylhydrazides that affect type III protein secretion in Salmonella enterica serovar typhimurium. Antimicrob Agents Chemother. 2007;51(8):2867-2876.

84. Muschiol S, Bailey L, Gylfe A, et al. A small-molecule inhibitor of type III secretion inhibits different stages of the infectious cycle of Chlamydia trachomatis. Proc Natl Acad Sci U S A. 2006;103(39):14566-14571.

85. Veenendaal AK, Sundin C, Blocker AJ. Small-molecule type III secretion system inhibitors block assembly of the Shigella type III secreton. J Bacteriol. 2009;191(2):563-570.

86. Momose Y, Hirayama K, Itoh K. Competition for proline between indigenous Escherichia coli and E. coli $\mathrm{O} 157: \mathrm{H} 7$ in gnotobiotic mice associated with infant intestinal microbiota and its contribution to the colonization resistance against E. coli O157:H7. Antonie Van Leeuwenhoek. 2008;94(2):165-171.

87. Momose Y, Hirayama K, Itoh K. Effect of organic acids on inhibition of Escherichia coli O157:H7 colonization in gnotobiotic mice associated with infant intestinal microbiota. Antonie Van Leeuwenhoek. 2008;93(1-2):141-149.

88. Fabich AJ, Jones SA, Chowdhury FZ, et al. Comparison of carbon nutrition for pathogenic and commensal Escherichia coli strains in the mouse intestine. Infect Immun. 2008;76(3):1143-1152.
89. Kamada N, Kim YG, Sham HP, et al. Regulated virulence controls the ability of a pathogen to compete with the gut microbiota. Science. 2012;336(6086):1325-1329.

90. Corbin BD, Seeley EH, Raab A, et al. Metal chelation and inhibition of bacterial growth in tissue abscesses. Science. 2008;319(5865): 962-965.

91. Flo TH, Smith KD, Sato S, et al. Lipocalin 2 mediates an innate immune response to bacterial infection by sequestrating iron. Nature. 2004;432(7019):917-921.

92. Lee JW, Helmann JD. Functional specialization within the Fur family of metalloregulators. Biometals. 2007;20(3-4):485-499.

93. Masse E, Gottesman S. A small RNA regulates the expression of genes involved in iron metabolism in Escherichia coli. Proc Natl Acad Sci U S A. 2002;99(7):4620-4625.

94. Leclerc JM, Dozois CM, Daigle F. Role of the Salmonella enterica serovar Typhi Fur regulator and small RNAs RfrA and RfrB in iron homeostasis and interaction with host cells. Microbiology. 2013; 159(pt 3):591-602.

95. Porcheron G, Habib R, Houle S, et al. The small RNA RyhB contributes to siderophore production and virulence of uropathogenic Escherichia coli. Infect Immun. 2014;82(12):5056-5068.

96. Mazmanian SK, Skaar EP, Gaspar AH, et al. Passage of hemeiron across the envelope of Staphylococcus aureus. Science. 2003; 299(5608):906-909.

97. Torres VJ, Pishchany G, Humayun M, Schneewind O, Skaar EP. Staphylococcus aureus IsdB is a hemoglobin receptor required for heme iron utilization. J Bacteriol. 2006;188(24):8421-8429.

98. Skaar EP, Gaspar AH, Schneewind O. IsdG and IsdI, heme-degrading enzymes in the cytoplasm of Staphylococcus aureus. J Biol Chem. 2004;279(1):436-443.

99. Friedman DB, Stauff DL, Pishchany G, Whitwell CW, Torres VJ, Skaar EP. Staphylococcus aureus redirects central metabolism to increase iron availability. PLoS Pathog. 2006;2(8):e87.

100. Stauff DL, Torres VJ, Skaar EP. Signaling and DNA-binding activities of the Staphylococcus aureus HssR-HssS two-component system required for heme sensing. J Biol Chem. 2007;282(36): 26111-26121.

101. Torres VJ, Stauff DL, Pishchany G, et al. A Staphylococcus aureus regulatory system that responds to host heme and modulates virulence. Cell Host Microbe. 2007;1(2):109-119.

102. Ghose C. Clostridium difficile infection in the twenty-first century. Emerg Microbes Infect. 2013;2(9):e62.

103. Eiseman B, Silen W, Bascom GS, Kauvar AJ. Fecal enema as an adjunct in the treatment of pseudomembranous enterocolitis. Surgery. 1958; 44(5):854-859.

104. Mattila E, Uusitalo-Seppala R, Wuorela M, et al. Fecal transplantation, through colonoscopy, is effective therapy for recurrent Clostridium difficile infection. Gastroenterology. 2012;142(3):490-496.

105. Youngster I, Hohmann EL. Fecal microbiota transplantation for Clostridium difficile infection - reply. JAMA. 2015;313(7):726.

106. Hamilton MJ, Weingarden AR, Sadowsky MJ, Khoruts A. Standardized frozen preparation for transplantation of fecal microbiota for recurrent Clostridium difficile infection. Am J Gastroenterol. 2012; 107(5):761-767.

107. Noinaj N, Guillier M, Barnard TJ, Buchanan SK. TonB-dependent transporters: regulation, structure, and function. Annu Rev Microbiol. 2010;64:43-60.

108. Yep A, McQuade T, Kirchhoff P, Larsen M, Mobley HL. Inhibitors of TonB function identified by a high-throughput screen for inhibitors of iron acquisition in uropathogenic Escherichia coli CFT073. MBio. 2014;5(2):e1089-e1113.

109. Brumbaugh AR, Smith SN, Mobley HL. Immunization with the yersiniabactin receptor, FyuA, protects against pyelonephritis in a murine model of urinary tract infection. Infect Immun. 2013;81(9): 3309-3316.

110. Alteri CJ, Hagan EC, Sivick KE, Smith SN, Mobley HL. Mucosal immunization with iron receptor antigens protects against urinary tract infection. PLoS Pathog. 2009;5(9):e1000586. 
111. Brumbaugh AR, Smith SN, Subashchandrabose S, et al. Blocking yersiniabactin import attenuates extraintestinal pathogenic Escherichia coli in cystitis and pyelonephritis and represents a novel target to prevent urinary tract infection. Infect Immun. 2015;83(4):1443-1450.

112. Arrowsmith $\mathrm{CH}$, Audia JE, Austin C, et al. The promise and peril of chemical probes. Nat Chem Biol. 2015;11(8):536-541.

113. Mike LA, Dutter BF, Stauff DL, et al. Activation of heme biosynthesis by a small molecule that is toxic to fermenting Staphylococcus aureus. Proc Natl Acad Sci U S A. 2013;110(20):8206-8211.

114. Dutter BF, Mike LA, Reid PR, et al. Decoupling activation of heme biosynthesis from anaerobic toxicity in a molecule active in Staphylococcus aureus. ACS Chem Biol. Epub 2016 Mar 4.

115. Kostakioti M, Hadjifrangiskou M, Hultgren SJ. Bacterial biofilms: development, dispersal, and therapeutic strategies in the dawn of the postantibiotic era. Cold Spring Harb Perspect Med. 2013;3(4): a010306.

116. Jacobsen SM, Stickler DJ, Mobley HL, Shirtliff ME. Complicated catheter-associated urinary tract infections due to Escherichia coli and Proteus mirabilis. Clin Microbiol Rev. 2008;21(1):26-59.

117. Kojic EM, Darouiche RO. Candida infections of medical devices. Clin Microbiol. 2004;17(2):255-267.

118. Anderson GG, Palermo JJ, Schilling JD, Roth R, Heuser J, Hultgren SJ. Intracellular bacterial biofilm-like pods in urinary tract infections. Science. 2003;301(5629):105-107.

119. Justice SS, Hung C, Theriot JA, et al. Differentiation and developmental pathways of uropathogenic Escherichia coli in urinary tract pathogenesis. Proc Natl Acad Sci U S A. 2004;101(5):1333-1338.

120. Blango MG, Mulvey MA. Persistence of uropathogenic Escherichia coli in the face of multiple antibiotics. Antimicrob Agents Chemother. 2010; 54(5):1855-1863.

121. Schilling JD, Lorenz RG, Hultgren SJ. Effect of trimethoprimsulfamethoxazole on recurrent bacteriuria and bacterial persistence in mice infected with uropathogenic Escherichia coli. Infect Immun. 2002;70(12):7042-7049.

122. Mulvey MA, Schilling JD, Hultgren SJ. Establishment of a persistent Escherichia coli reservoir during the acute phase of a bladder infection. Infect Immun. 2001;69(7):4572-4579.

123. Garcia-Medina R, Dunne WM, Singh PK, Brody SL. Pseudomonas aeruginosa acquires biofilm-like properties within airway epithelial cells. Infect Immun. 2005;73(12):8298-8305.

124. Rosen DA, Pinkner JS, Jones JM, Walker JN, Clegg S, Hultgren SJ. Utilization of an intracellular bacterial community pathway in Klebsiella pneumoniae urinary tract infection and the effects of FimK on type 1 pilus expression. Infect Immun. 2008;76(7):3337-3345.

125. Davis KM, Mohammadi S, Isberg RR. Community behavior and spatial regulation within a bacterial microcolony in deep tissue sites serves to protect against host attack. Cell Host Microbe. 2015;17(1):21-31.

126. Bigger J. Treatment of staphylococcal infections with penicillin by intermittent sterilisation. Lancet. 1944;244(6320):497-500.

127. Vega NM, Allison KR, Khalil AS, Collins JJ. Signaling-mediated bacterial persister formation. Nat Chem Biol. 2012;8(5):431-433.

128. Moker N, Dean CR, Tao J. Pseudomonas aeruginosa increases formation of multidrug-tolerant persister cells in response to quorum-sensing signaling molecules. J Bacteriol. 2010;192(7):1946-1955.

129. Oggioni MR, Trappetti C, Kadioglu A, et al. Switch from planktonic to sessile life: a major event in pneumococcal pathogenesis. Mol Microbiol. 2006;61(5):1196-1210.

130. Havarstein LS, Coomaraswamy G, Morrison DA. An unmodified heptadecapeptide pheromone induces competence for genetic transformation in Streptococcus pneumoniae. Proc Natl Acad Sci US A. 1995; 92(24):11140-11144.

131. Oggioni MR, Iannelli F, Ricci S, et al. Antibacterial activity of a competence-stimulating peptide in experimental sepsis caused by Streptococcus pneumoniae. Antimicrob Agents Chemother. 2004;48(12):4725-4732

132. LaFleur MD, Lucumi E, Napper AD, Diamond SL, Lewis K. Novel high-throughput screen against Candida albicans identifies antifungal potentiators and agents effective against biofilms. J Antimicrob Chemother. 2011;66(4):820-826.
133. Fazly A, Jain C, Dehner AC, et al. Chemical screening identifies filastatin, a small molecule inhibitor of Candida albicans adhesion, morphogenesis, and pathogenesis. Proc Natl Acad Sci U S A. 2013; 110(33):13594-13599.

134. Pierce CG, Chaturvedi AK, Lazzell AL, et al. A novel small molecule inhibitor of Candida albicans biofilm formation, filamentation and virulence with low potential for the development of resistance. NPJ Biofilms Microbiomes. Epub 2015 Aug 12;1.

135. Lafleur MD, Sun L, Lister I, et al. Potentiation of azole antifungals by 2-adamantanamine. Antimicrob Agents Chemother. 2013;57(8): 3585-3592.

136. Blango MG, Ott EM, Erman A, Veranic P, Mulvey MA. Forced resurgence and targeting of intracellular uropathogenic Escherichia coli reservoirs. PLoS One. 2014;9(3):e93327.

137. Robino L, Scavone P, Araujo L, Algorta G, Zunino P, Vignoli R. Detection of intracellular bacterial communities in a child with Escherichia coli recurrent urinary tract infections. Pathog Dis. 2013; 68(3):78-81.

138. Khasriya R, Sathiananthamoorthy S, Ismail S, et al. Spectrum of bacterial colonization associated with urothelial cells from patients with chronic lower urinary tract symptoms. J Clin Microbiol. 2013; 51(7):2054-2062.

139. Rosen DA, Hooton TM, Stamm WE, Humphrey PA, Hultgren SJ. Detection of intracellular bacterial communities in human urinary tract infection. PLoS Med. 2007;4(12):e329.

140. Spoering AL, Lewis K. Biofilms and planktonic cells of Pseudomonas aeruginosa have similar resistance to killing by antimicrobials. J Bacteriol. 2001;183(23):6746-6751.

141. LaFleur MD, Kumamoto CA, Lewis K. Candida albicans biofilms produce antifungal-tolerant persister cells. Antimicrob Agents Chemother. 2006;50(11):3839-3846.

142. Lafleur MD, Qi Q, Lewis K. Patients with long-term oral carriage harbor high-persister mutants of Candida albicans. Antimicrob Agents Chemother. 2010;54(1):39-44.

143. Mulcahy LR, Burns JL, Lory S, Lewis K. Emergence of Pseudomonas aeruginosa strains producing high levels of persister cells in patients with cystic fibrosis. J Bacteriol. 2010;192(23):6191-6199.

144. Brotz-Oesterhelt H, Beyer D, Kroll HP, et al. Dysregulation of bacterial proteolytic machinery by a new class of antibiotics. Nat Med. 2005;11(10):1082-1087.

145. Conlon BP, Nakayasu ES, Fleck LE, et al. Activated ClpP kills persisters and eradicates a chronic biofilm infection. Nature. 2013; 503(7476):365-370.

146. Davies DG, Parsek MR, Pearson JP, Iglewski BH, Costerton JW, Greenberg EP. The involvement of cell-to-cell signals in the development of a bacterial biofilm. Science. 1998;280(5361):295-298.

147. Pearson JP, Feldman M, Iglewski BH, Prince A. Pseudomonas aeruginosa cell-to-cell signaling is required for virulence in a model of acute pulmonary infection. Infect Immun. 2000;68(7):4331-4334.

148. Wu H, Song Z, Hentzer M, et al. Synthetic furanones inhibit quorumsensing and enhance bacterial clearance in Pseudomonas aeruginosa lung infection in mice. J Antimicrob Chemother. 2004;53(6):1054-1061.

149. Hentzer M, Wu H, Andersen JB, et al. Attenuation of Pseudomonas aeruginosa virulence by quorum sensing inhibitors. EMBO J. 2003; 22(15):3803-3815.

150. Hadjifrangiskou M, Kostakioti M, Chen SL, Henderson JP, Greene SE, Hultgren SJ. A central metabolic circuit controlled by QseC in pathogenic Escherichia coli. Mol Microbiol. 2011;80(6):1516-1529.

151. Kostakioti M, Hadjifrangiskou M, Pinkner JS, Hultgren SJ. QseCmediated dephosphorylation of QseB is required for expression of genes associated with virulence in uropathogenic Escherichia coli. Mol Microbiol. 2009;73(6):1020-1031.

152. Alteri CJ, Lindner JR, Reiss DJ, Smith SN, Mobley HL. The broadly conserved regulator PhoP links pathogen virulence and membrane potential in Escherichia coli. Mol Microbiol. 2011;82(1):145-163.

153. Macfarlane EL, Kwasnicka A, Hancock RE. Role of Pseudomonas aeruginosa $\mathrm{PhoP}$-phoQ in resistance to antimicrobial cationic peptides and aminoglycosides. Microbiology. 2000;146(pt 10):2543-2554. 
154. Miller SI, Kukral AM, Mekalanos JJ. A two-component regulatory system (phoP phoQ) controls Salmonella typhimurium virulence. Proc Natl Acad Sci U S A. 1989;86(13):5054-5058.

155. Dalebroux ZD, Miller SI. Salmonellae PhoPQ regulation of the outer membrane to resist innate immunity. Curr Opin Microbiol. 2014;17: 106-113.

156. Hohmann EL, Oletta CA, Killeen KP, Miller SI. phoP/phoQ-deleted Salmonella typhi (Ty800) is a safe and immunogenic single dose typhoid fever vaccine in volunteers. J Infect Dis. 1996;173(6):1408-1414.

157. Hohmann EL, Oletta CA, Miller SI. Evaluation of a phoP/phoQdeleted, aroA-deleted live oral Salmonella typhi vaccine strain in human volunteers. Vaccine. 1996;14(1):19-24.

158. Lenz DH, Mok KC, Lilley BN, Kulkarni RV, Wingreen NS, Bassler BL. The small RNA chaperone Hfq and multiple small RNAs control quorum sensing in Vibrio harveyi and Vibrio cholerae. Cell. 2004; 118(1):69-82.

159. Lenz DH, Miller MB, Zhu J, Kulkarni RV, Bassler BL. CsrA and three redundant small RNAs regulate quorum sensing in Vibrio cholerae. Mol Microbiol. 2005;58(4):1186-1202.

160. Pichon C, Felden B. Small RNA genes expressed from Staphylococcus aureus genomic and pathogenicity islands with specific expression among pathogenic strains. Proc Natl Acad Sci U S A. 2005;102(40): 14249-14254.

161. Wilderman PJ, Sowa NA, FitzGerald DJ, et al. Identification of tandem duplicate regulatory small RNAs in Pseudomonas aeruginosa involved in iron homeostasis. Proc Natl Acad Sci U S A. 2004; 101(26):9792-9797.

162. Coornaert A, Lu A, Mandin P, Springer M, Gottesman S, Guillier M. MicA sRNA links the PhoP regulon to cell envelope stress. Mol Microbiol. 2010;76(2):467-479.

163. Coornaert A, Chiaruttini C, Springer M, Guillier M. Post-transcriptional control of the Escherichia coli PhoQ-PhoP two-component system by multiple sRNAs involves a novel pairing region of GcvB. PLoS Genet. 2013;9(1):e1003156.

164. Freeman JA, Bassler BL. A genetic analysis of the function of LuxO, a two-component response regulator involved in quorum sensing in Vibrio harveyi. Mol Microbiol. 1999;31(2):665-677.

165. Freeman JA, Bassler BL. Sequence and function of LuxU: a twocomponent phosphorelay protein that regulates quorum sensing in Vibrio harveyi. J Bacteriol. 1999;18(3):899-906.

166. Neiditch MB, Federle MJ, Pompeani AJ, et al. Ligand-induced asymmetry in histidine sensor kinase complex regulates quorum sensing. Cell. 2006;126(6):1095-1108.

167. Swem LR, Swem DL, O'Loughlin CT, et al. A quorum-sensing antagonist targets both membrane-bound and cytoplasmic receptors and controls bacterial pathogenicity. Mol Cell. 2009;35(2):143-153.

168. Lilley BN, Bassler BL. Regulation of quorum sensing in Vibrio harveyi by LuxO and sigma-54. Mol Microbiol. 2000;36(4):940-954.
169. Tu KC, Bassler BL. Multiple small RNAs act additively to integrate sensory information and control quorum sensing in Vibrio harveyi. Genes Dev. 2007;21(2):221-233.

170. Rutherford ST, Valastyan JS, Taillefumier T, Wingreen NS, Bassler BL. Comprehensive analysis reveals how single nucleotides contribute to noncoding RNA function in bacterial quorum sensing. Proc Natl Acad Sci U S A. 2015;112(44):E6038-E6047.

171. Shao Y, Bassler BL. Quorum regulatory small RNAs repress type VI secretion in Vibrio cholerae. Mol Microbiol. 2014;92(5):921-930.

172. Shao Y, Feng L, Rutherford ST, Papenfort K, Bassler BL. Functional determinants of the quorum-sensing non-coding RNAs and their roles in target regulation. EMBO J. 2013;32(15):2158-2171.

173. Rutherford ST, van Kessel JC, Shao Y, Bassler BL. AphA and LuxR/ HapR reciprocally control quorum sensing in vibrios. Genes Dev. 2011;25(4):397-408.

174. Rasko DA, Moreira CG, Li de R, et al. Targeting QseC signaling and virulence for antibiotic development. Science. 2008;321(5892):1078-1080.

175. Curtis MM, Russell R, Moreira CG, et al. QseC inhibitors as an antivirulence approach for Gram-negative pathogens. MBio. 2014; 5(6): 02165

176. Guckes KR, Kostakioti M, Breland EJ, et al. Strong cross-system interactions drive the activation of the QseB response regulator in the absence of its cognate sensor. Proc Natl Acad Sci US A. 2013;110(41): 16592-16597.

177. Kostakioti M, Hadjifrangiskou M, Cusumano CK, Hannan TJ, Janetka JW, Hultgren SJ. Distinguishing the contribution of type 1 pili from that of other QseB-misregulated factors when QseC is absent during urinary tract infection. Infect Immun. 2012;80(8):2826-2834.

178. Ng WL, Perez L, Cong J, Semmelhack MF, Bassler BL. Broad spectrum pro-quorum-sensing molecules as inhibitors of virulence in vibrios. PLoS Pathog. 2012;8(6):e1002767.

179. Perez LJ, Karagounis TK, Hurley A, Bassler BL, Semmelhack MF. Highly potent, chemically stable quorum sensing agonists for Vibrio cholerae. Chem Sci. 2014;5(1):151-155.

180. Higgins DA, Pomianek ME, Kraml CM, Taylor RK, Semmelhack MF, Bassler BL. The major Vibrio cholerae autoinducer and its role in virulence factor production. Nature. 2007;450(7171):883-886.

181. Wei Y, Perez LJ, Ng WL, Semmelhack MF, Bassler BL. Mechanism of Vibrio cholerae autoinducer-1 biosynthesis. ACS Chem Biol. 2011;6(4):356-365.

182. Tschowri N, Busse S, Hengge R. The BLUF-EAL protein YcgF acts as a direct anti-repressor in a blue-light response of Escherichia coli. Genes Dev. 2009;23(4):522-534.

183. Obama B. Executive order 13676: combating antibiotic-resistant bacteria. In: House TW, ed. Vol 184. Washington, DC: Federal Register; 2014:56931-56935.

184. National action plan for combating antibiotic-resistant bacteria. In: Services USDoHaH, ed: U.S. Government Publishing Office; 2015.
Drug Design, Development and Therapy

\section{Publish your work in this journal}

Drug Design, Development and Therapy is an international, peerreviewed open-access journal that spans the spectrum of drug design and development through to clinical applications. Clinical outcomes, patient safety, and programs for the development and effective, safe, and sustained use of medicines are a feature of the journal, which

\section{Dovepress}

has also been accepted for indexing on PubMed Central. The manuscript management system is completely online and includes a very quick and fair peer-review system, which is all easy to use. Visit http://www.dovepress.com/testimonials.php to read real quotes from published authors. 